\title{
DIDÁTICA E PROJETO DE PRODUTO 4: A COERÊNCIA DE UM DESAFIO METODOLÓGICO COLABORATIVO
}

Dr. Eduardo Américo Pedrosa Loureiro Júnior

edoardo@patio.com.br

Dra. Anna Lúcia dos Santos Vieira e Silva Universidade Federal do Ceará annalucialilu@gmail.com

\author{
Carlos Eugênio Moreira de Sousa \\ Universidade Federal do Ceará \\ eugeniomoreira@gmail.com \\ Lara Dias Monteiro Josino \\ Universidade Federal do Ceará \\ laradiasmj@gmail.com \\ Levi Holanda Castelo Branco \\ Universidade Federal do Ceará \\ levi.hcbranco@gmail.com
}

Resumo: O objetivo deste artigo é apresentar aplicações da disciplina Didática I, da Faculdade de Educação, na disciplina Projeto de Produto 4 (PP4), do curso de Design, como resultado de um desafio metodológico de integrar conteúdo e prática em uma proposta colaborativa. O método de Didática tinha três linhas: autoensino, didática e projeto cidadão. O conteúdo de PP4, em escala de complexidade crescente durante o curso, abrange uma somatória de tendências contemporâneas em design que incluem sua relação com sistemas dinâmicos e complexos, ecodesign, design social, open design e toda gama de possibilidades de design colaborativo que podem caber no termo co-design. Da união dos modos de ensino-aprendizagem da Didática I com o conteúdo colaborativo de Projeto, nasceu uma experiência singular em que alunos e professores criaram, projetaram e decidiram como e o que quiseram fazer no sistema dinâmico e complexo que é a própria disciplina PP4. Com base na pesquisaação (TRIPP, 2005; TOLEDO e JACOBI, 2013), o processo de projeto em design se deu em cinco etapas: 1) pesquisa; 2) metaprojeto; 3) projeto e prototipagem; 4) intervenção urbana; 5) reflexões.

Palavras-chave: didática, projeto em design, metodologia colaborativa, metaprojeto, pesquisa-ação.

Abstract: The purpose of this article is to present applications of the Didactics I subject, from the Faculty of Education, in the Product Project 4 (PP4) subject, from the Design graduation course, as a result of a methodological challenge to integrate content and practice in a collaborative proposal. The Didactic I method had three lines: self teaching, didactics and citizenship project. The content of PP4, in a scale of increasing complexity during the Design graduation course, covers a sum of contemporary trends in design, which includes their relationship with 
dynamic and complex systems, eco-design, social design, open design and a full range of collaborative design possibilities that can fit in the co-design term. From the union of the teaching-learning methods of Didactic I with the collaborative content of Project, a unique experience was born, in which students and teachers created, designed and decided how and what they wanted to do in the dynamic and complex system which is the subject itself. Based on action research (TRIPP, 2005; TOLEDO and JACOBI, 2013), the process in PP4 took place in five steps: 1) research; 2) metaproject; 3) project and prototyping; 4) urban intervention; 5) reflexions.

Keywords: didactics, design project, collaborative methodology, metaproject, action research.

\section{INTRODUÇÃO}

Dentro do plano pedagógico do curso de Design da Universidade Federal do Ceará (UFC), o processo de formação é estruturado segundo três ciclos: o Ciclo de Fundamentação, o Ciclo Profissionalizante e o Ciclo de Conclusão. A disciplina de Projeto de Produto 4, cujo processo se pretende explorar no desenvolvimento deste artigo, está presente no último semestre do Ciclo profissionalizante e representa o final da cadeia de projetos de produto. Em seus objetivos, pretende: 1-) abordar temas relacionados ao design em relação ao espaço a partir dos parâmetros da comunicação, acessibilidade, sustentabilidade e design social; 2-) relacionar metodologias de projeto que envolvem o design de interiores, soluções de detalhes construtivos, sinalização de ambientes, acessibilidade, equipamentos e suas adequações em espaços públicos, coletivos e urbanos; 3-) entender como metodologias de projeto colaborativas e participativas podem contribuir em propostas de design social.

Uma rápida análise dos temas propostos mostra que a abrangência é um problema a ser superado. Como, então, ser capaz de fazer com que o conteúdo caiba em um semestre sem adotar uma atitude reducionista? Como tratar com coerência a disciplina no que tange seu conteúdo, a metodologia de projeto e a proposta pedagógica? É possível abranger os três níveis e, ao mesmo tempo, considerar o interesse específico de cada aluno?

Tomando como oportuna a participação de um dos docentes responsáveis pela disciplina em uma outra, ministrada na Faculdade de Educação da UFC (no período 2014.2), procedeu-se a uma experiência: trazer para dentro do Curso de Design as práticas da disciplina Didática I.

Em Didática foram apresentadas três linhas de ensino e aprendizagem: autoensino, didática propriamente dita e projeto cidadão. As linhas foram definidas a partir de três perguntas, respectivamente: $O$ que eu quero aprender? $\mathrm{O}$ que os outros querem que eu aprenda? O que eu quero que os outros aprendam?

Este artigo aborda esta integração por meio da apresentação e análise do processo das disciplinas e dos resultados obtidos em cada etapa da disciplina de Projeto de Produto 4 (no período 2015.2).

O processo metodológico se fundamenta a partir do sentido de colaboração abordado sob o prisma de pessoas que trabalham juntas como copesquisadoras em um projeto no qual possuem igual participação (TRIPP, 2005, p. 454). Outra apreciação 
do conceito muito bem estruturada é oferecida por Torres (2004, p. 50), que apresenta uma proposta colaborativa como a que implica a participação ativa do aluno no processo de aprendizagem; a construção coletiva do conhecimento, que emerge da troca entre pares, das atividades práticas dos alunos, de suas reflexões, de seus debates e questionamentos; a mediação da aprendizagem feita por professores e tutores; interatividade entre os diversos atores que atuam no processo; estimulação dos processos de expressão e comunicação; flexibilização dos papéis no processo das comunicações e das relações a fim de permitir a construção coletiva do saber; sistematização do planejamento, do desenvolvimento e da avaliação das atividades; aceitação das diversidades e diferenças entre alunos; desenvolvimento da autonomia do aluno no processo ensino-aprendizagem; valorização da liberdade com responsabilidade; comprometimento com a autoria; maior valorização do processo que do produto.

Na primeira aula, o professor de Didática perguntou: "Qual é seu sentimento?". Na pergunta dos professores de projeto: “O que vocês querem dessa disciplina?". Sentir e querer se colocaram como alicerces de uma construção de saberes em uma arquitetura móvel, flexível, mas suficientemente estruturada para que o espaço de troca fosse propício. Professores aprendizes, alunos capazes de profetizar sua autonomia.

\title{
2. PRIMEIRA LIÇÃO
}

\begin{abstract}
"Estávamos, assim, tentando uma educação que nos parecia a de que precisávamos. Identificada com as condições de nossa realidade. Realmente instrumental, porque integrada ao nosso tempo e ao nosso espaço e levando o homem a refletir sobre sua ontológica vocação de ser sujeito." (Freire, 1967, p. 106)
\end{abstract}

Na primeira linha de Didática, cada estudante listava três coisas que gostaria de aprender. Qualquer coisa. Não precisava ter qualquer conexão com o conteúdo da disciplina. Em seguida, cada estudante listava três coisas que aprendeu, coisas realmente bem aprendidas, que o estudante dominava agora sem esforço. Para cada uma das três coisas aprendidas, foram listados pelo menos três passos (métodos, técnicas) usados para o efetivo aprendizado. Dessa forma, cada estudante, possuía pelo menos nove maneiras de aprendizagem que funcionavam a partir de sua própria experiência. O estudante escolhia então um dos três itens da lista de coisas que gostaria de aprender e definia, a partir de sua lista pessoal de métodos, três estratégias que melhor poderiam se aplicar ao aprendizado do item escolhido. Dessa forma, cada estudante já tinha o objetivo (aprender tal coisa) e a metodologia (indicações de como aprender) de seu projeto de autoensino. Em seguida, o estudante completava o seu plano de autoensino com o conteúdo (o que deveria ser especificamente aprendido) e com a avaliação (como monitoraria o seu processo de aprendizado). Durante o semestre, o estudante procuraria aprender aquilo que desejava tendo por principal professor a si mesmo (autoensino), pensando o professor não como alguém que domina previamente o conteúdo, mas como aquele que sabe organizar o processo de aprendizagem. Por duas ou três vezes, cada estudante traria seu aprendizado para a sala de aula, realizando (individualmente ou em grupo) atividades relacionadas ao seu projeto de autoensino. 
Este procedimento de didática foi aplicado em projeto nos primeiros passos, onde os alunos primeiramente aceitaram a proposta de construir com os professores a própria disciplina, com a necessidade de escolher, na amplitude de temas, o que e como trabalhar durante o semestre. Desta forma, todos foram responsáveis por definir seus interesses e configurar seu próprio aprendizado no decorrer do processo, com foco na participação ativa do grupo, nas tomadas de decisões sobre assuntos que lhes diziam respeito, por meio de um "envolvimento dos sujeitos da pesquisa em um processo de reflexão, análise da realidade, produção de conhecimentos e enfrentamento dos problemas." (TOLEDO, JACOBI, 2013, p. 156)

Por unanimidade, foi decidido que o projeto sairia do papel, dos protótipos, para ser efetivamente realizado.

\section{PESQUISA-BLOG}

"Uma proposta de pesquisa, que se concentra no próprio processo de pesquisa-ação, tem notória dificuldade de ser aprovada por um comitê de pesquisa da universidade simplesmente porque não é possível especificar com antecedência qual conhecimento será obtido nem quais resultados práticos serão alcançados. Isso porque os resultados de cada ciclo determinarão o que acontecerá a seguir e não há como dizer de saída aonde o processo levará." (TRIPP, 2005, p.459)

Etapas da disciplina de Projeto de Produto 4

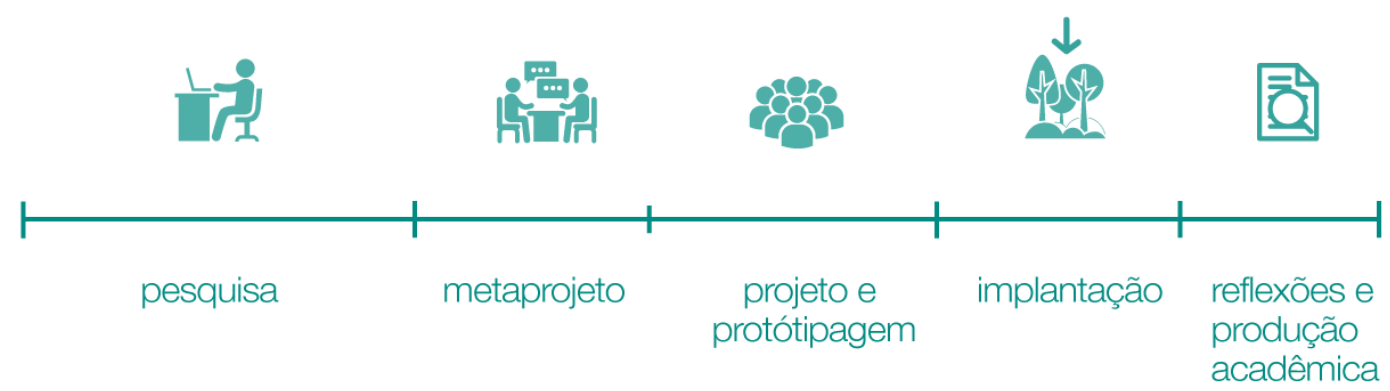

Imagem 1- Etapas da Disciplina de PP4.

Elaborado pelo co-autor, com base na pesquisa realizada.

Na segunda linha da disciplina de Didática, cada estudante listava três coisas que gostaria de aprender a respeito do processo de ensino-aprendizagem. Sincronicamente, aquilo que os estudantes desejam aprender atendia amplamente o conteúdo da ementa (aquilo que os outros, a comunidade acadêmica deseja que cada estudante aprenda), dessa forma o professor ficou mais à vontade para deixar os estudantes seguirem suas intenções de estudo. Durante o semestre, cada estudante realizava individualmente (em duplas ou em trios) uma atividade referente a cada um dos três assuntos de Didática que gostaria de aprender. Sempre que necessário, o professor realizava atividades adicionais, conduzidas por ele próprio, com o objetivo de garantir o tratamento de assuntos essenciais à disciplina.

As atividades realizadas pelos estudantes nessas duas primeiras linhas precisavam obedecer a três itens: entrega de planejamento prévio (para que as atividades não fossem realizadas com excesso de improviso), interação entre os estudantes (para que a atividade que visa a participação ativa do estudante não 
levasse à passividade do restante da turma, como às vezes acontece em seminários) e respeito ao tempo estipulado (para que os estudantes aprendam a lidar de forma prática com esse condicionamento tão importante da prática didática).

O desafio da primeira etapa de PP4 foi um levantamento de conteúdo consistente que revelasse o interesse de cada aluno e o tornasse acessível a todos, e, de certa maneira, construir uma referência prática da capacidade de realização do nosso objetivo. A decisão coletiva foi a elaboração de um blog.

Um mês para a construção do blog, como uma ferramenta colaborativa em que se expõem os interesses e conhecimentos que envolvem o amplo espectro da disciplina, dentro dos parâmetros "complexidade, dinâmica e sistemas.". As informações foram organizadas em duas instâncias: através de categorias e através de tags[1]. Cada post se enquadrava em uma categoria e possuía quantas tags o autor/aluno julgasse necessárias. A organização do blog e a comunicação interna da disciplina aconteceram por um grupo fechado do Facebook, como a seguinte comunicação logo no início da disciplina:

"Fizemos uma conversa na aula passada sobre os encaminhamentos para a disciplina e acordamos o seguinte: Temos aquela lousa interativa que elenca uma série de áreas temáticas que podem ser trabalhadas em PP4. A ideia é que as coisas (pesquisas, exemplos etc.) sejam do interesse de vocês e tenham a ver com esse universo. Isso vai gerar um conteúdo para balizar a escolha do tema do projeto. Teremos um material que formará um sistema de informações interligadas (nem sempre o material trazido tem a ver com um só tema), que precisa ser dinâmico e colaborativo. Pra organizar essa coisa toda, sugerimos a criação de um blog administrado por todos. Assim, cada material trazido pode vir acompanhado de uma espécie de resenha, tudo fica disponível a todos, há a possibilidade de comentar nas postagens uns os outros e o sistema de tags vai ajudar muito na organização. Essa é a ideia geral, vamos criar as regras específicas do que deve ter cada post, no mínimo. Se ninguém se opuser, criamos a estrutura básica e publicamos aqui para alimentarmos. Mas se alguém quiser sugerir outro, podemos discutir sobre. Lembrando que esse trabalho foi proposto na aula passada e deve ser entregue na próxima aula."

A primeira categoria do blog era "Material teórico" e englobava publicações em geral sobre os temas da ampla abordagem da disciplina em artigos, trechos de livros e/ou trabalhos acadêmicos, desde a gênese dos termos até suas relações com o design. "Aplicações no mundo" era a segunda categoria e implicava em exemplos de como o Design e o designer se inserem em um contexto dinâmico e de alta complexidade, de maneira sistêmica e qualitativa, na modificação de uma realidade posta. Foram materiais retirados da própria web, de outros blogs ou sites especializados, além de livros e artigos com informações a respeito de um projeto, de preferência em mais de uma fonte. Como o objetivo era aplicar na realidade, "Possibilidades em nossa cidade" era a terceira categoria do blog, com conteúdo mais livre, fontes diversas como reportagens, fotos de acervo próprio, entrevistas, etc.

Apesar das propostas apresentarem um post de cada categoria, se observou que a terceira era a mais complexa dentro do grupo, reflexo de um bloqueio para identificar e idealizar situações e espaços específicos com necessidades de intervenção. Uma questão que retornou mais à frente durante a disciplina - Qual o 
problema do meu contexto local que necessita ser reprojetado? Onde podemos projetar que há a demanda de todos esses conceitos contemporâneos de design?

O oposto se observou no segundo tópico, que apresentou uma pesquisa muito mais abrangente e pulsante de diversas aplicações contemporâneas do design. A facilidade de pesquisa e o fascínio por experimentações e projetos externos foram grandes motivadores disto.

\section{Tags mais utilizadas} por quantidade

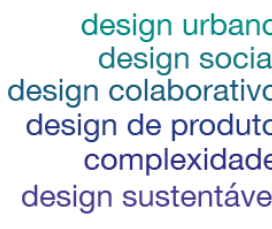

空
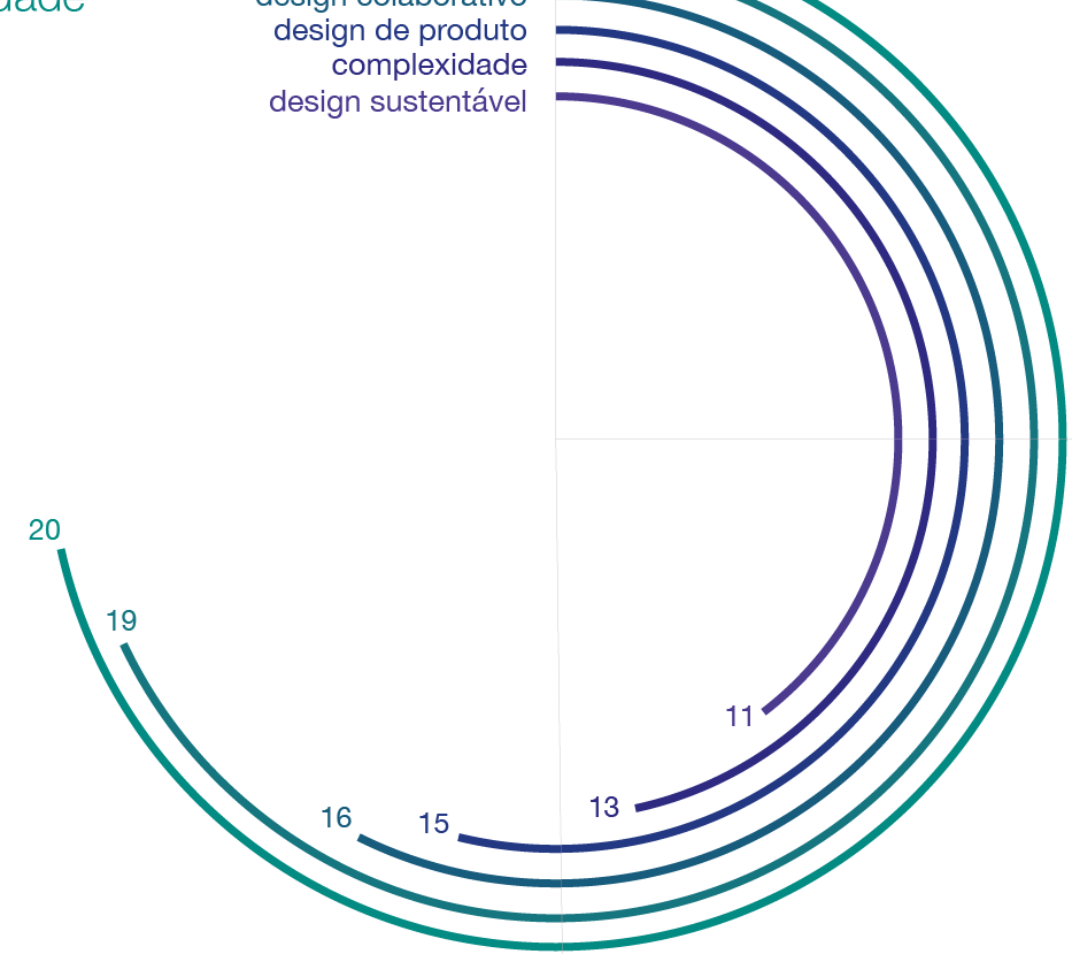

Imagem 2- Infográfico das tags mais utilizadas.

Elaborado por co-autor, com base na pesquisa.

\section{METAPROJETO}

“(...) parte do Metadesign é reconhecer como a realidade, enquanto representação de um mundo que provavelmente estará além de nossa compreensão absoluta, é um objeto de trabalho, uma obra individual e/ou coletiva, e que, quando ela torna-se coletiva, é ainda outro processo de construção de uma realidade comungada." (VASSÃO, 2010, p.16)

Depois do levantamento de conteúdo, foi estudado e realizado, na segunda etapa, o metaprojeto (CARDOSO, 2010), uma estrutura organizativa dos processos previstos, com os parâmetros a serem definidos nas etapas seguintes de projeto, prototipagem, realização, documentação e trabalho integrado com a disciplina Projeto Gráfico 4, previsto para o último mês. A metodologia para o estudo bibliográfico foi aplicada a partir da sugestão de um dos alunos que havia participado de um grupo de aprendizagem cooperativa. Foram divididos grupos de três pessoas e cada grupo estudava um capítulo do livro e compartilhava com os outros grupos em aula. 
Com a formação de um entendimento de como proceder, e a partir da premissa de que "ao planejar, planeja-se o que planejar, começa-se a planejar, monitora-se o progresso do plano e avalia-se o plano antes de ir adiante para implementá-lo" (TRIPP, 2005, p. 454), seguimos a elaboração do metaprojeto, que se deu por meio de montagens de lousas interativas até chegarmos aos cinco parâmetros de projeto: "1) elementos urbanos; 2) itinerantes, 3) interativos; 4) lúdico-educativos; 5) em praças.".
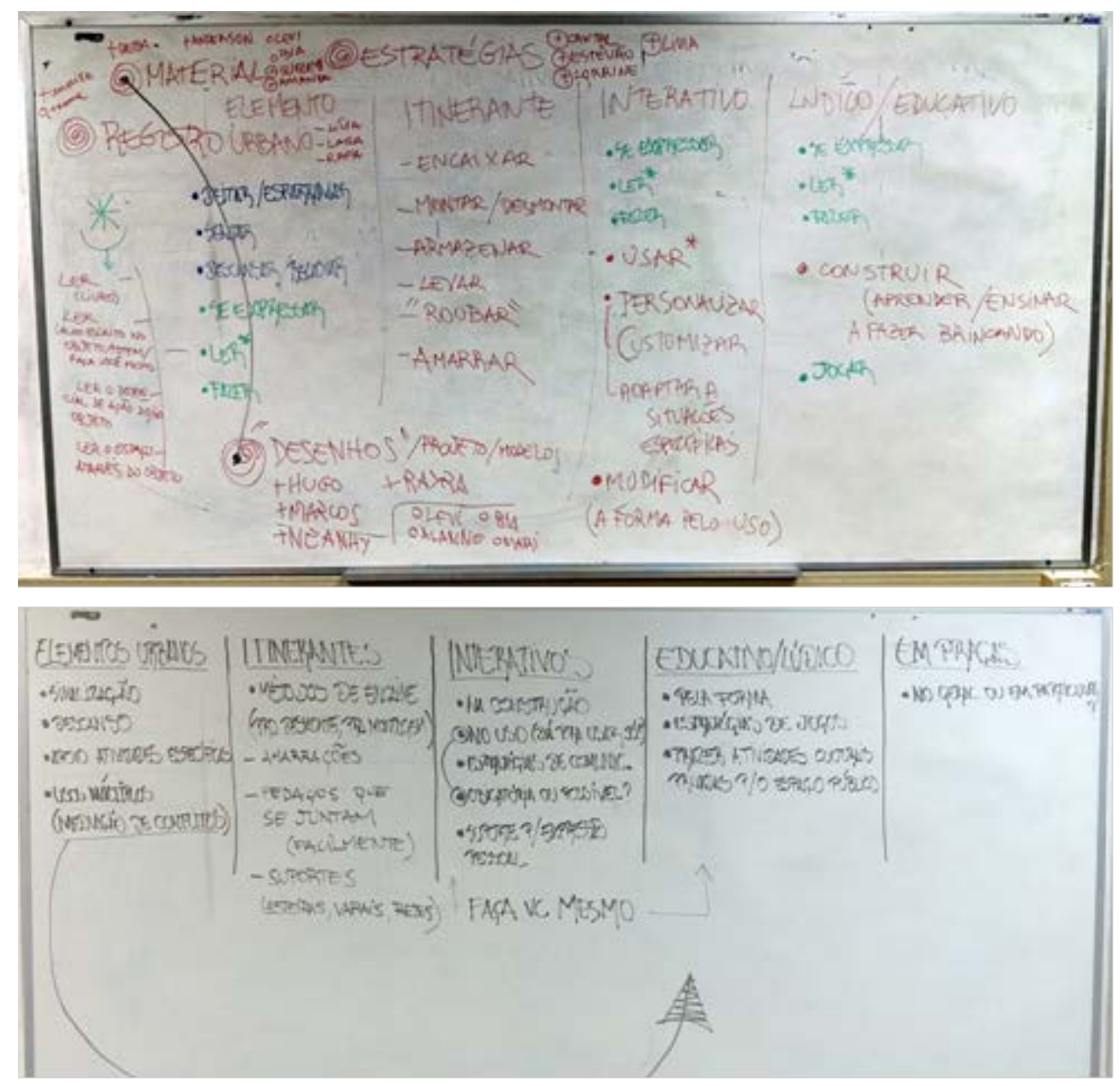

Imagens 3 e 4- Lousas interativas, 25 de novembro de 2015.

Fonte: Lorrine Sampaio.

\section{PROJETO E PROTOTIPAGEM}

"O paradoxo de aprender uma competência realmente nova é este: um estudante não pode inicialmente entender o que precisa aprender; ele pode aprendê-lo somente educando a si mesmo e só pode educar-se começando a fazer o que ainda não entende. (...) Espera-se que ele mergulhe na atividade de projetar, tentando, desde o início, fazer o que ainda não sabe como fazer, de modo a ganhar o tipo de experiência que o ajudará a aprender o que significa o projeto." (SCHÖN, 2000, p. 79)

Dentro do cronograma estipulado pelo grupo, o início do processo projetual se deu por meio de uma série de tomadas de decisões a partir dos parâmetros do 
metaprojeto. Como metodologia, inicialmente os alunos trouxeram ideias individuais com a liberdade de expressá-las em diferentes linguagens. Cada aluno trouxe mais de uma ideia.

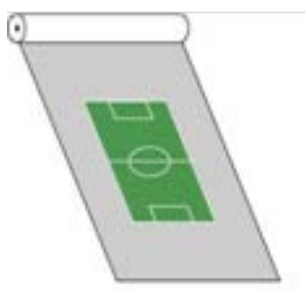

Esteiras interativas com estampas diversas de jogos coma, futebol de botio, twister, damas e etc. Além de um local para descanso sobre a grama das praças. Estimularia a ocupaçáo da praça.

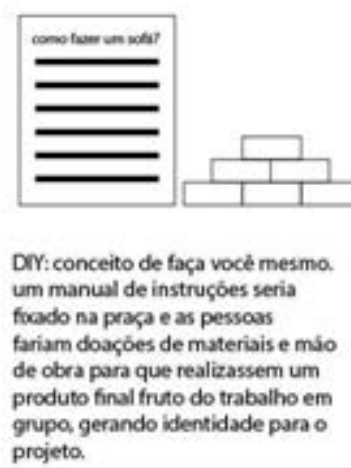

projeto.

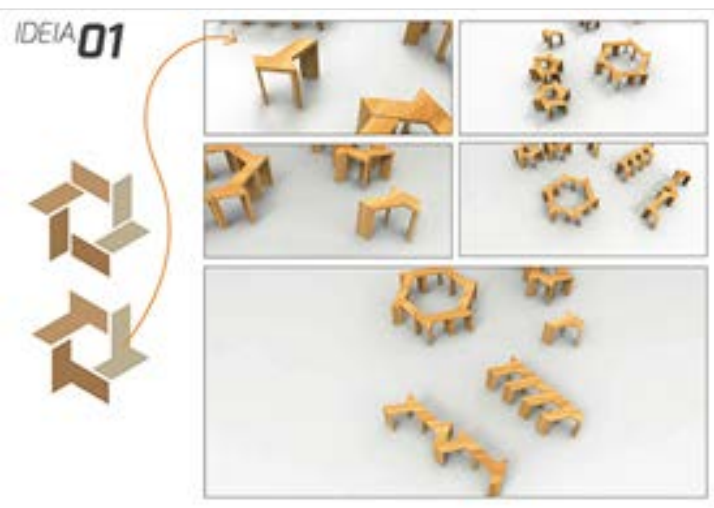

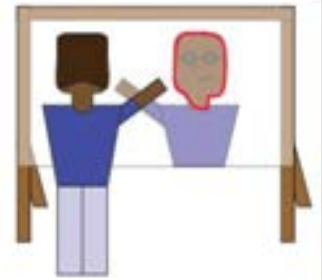

Quem é vocè? Intervença cujas pessoas realizariam um autoretrato sobre um plastico fixado sobre um espelho

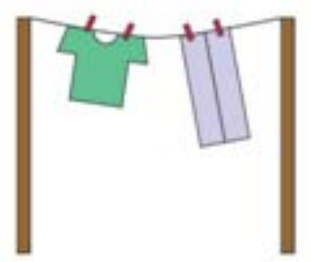

Tem uma roupa que njo serve mais? doe-a para um moradoe de nas que pode estar precisanda.
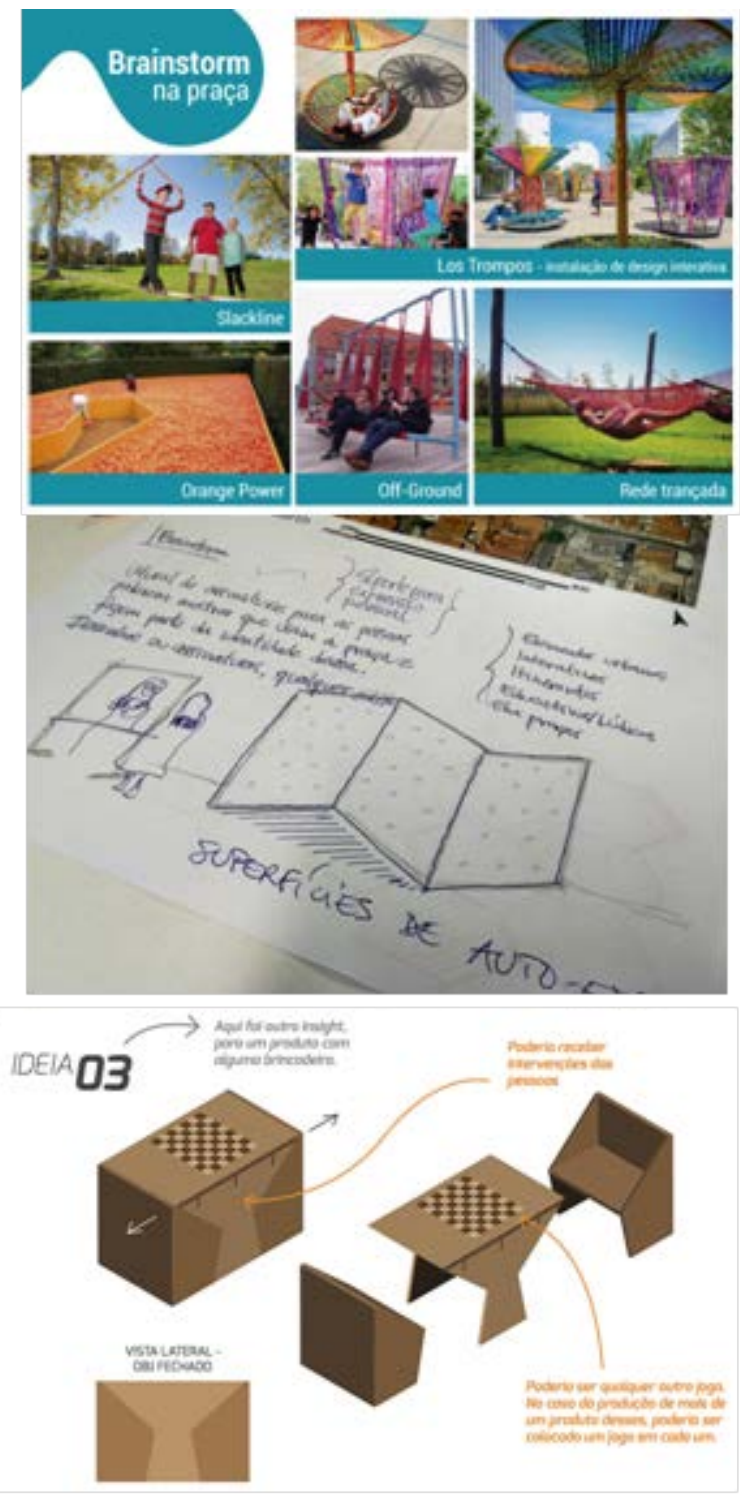

Imagem 5 - Ideias de Lucas, Suelen, Rafael e Marcos.

Com o conjunto de ideias, em aula fizemos um brainstorm coletivo, em grupos de três pessoas. Nesse processo, surgiam novas ideias a partir das junções ou de caminhos indicados por outras novas possibilidade, que nasceram na interação. Os grupos se juntaram até chegar a uma seleção de possibilidades que configurou dois grandes grupos, cada um com uma proposta de projeto: Tramas; e Encaixes. Com uma mesma metodologia experimental (Schön, 2000) e de pesquisa-ação (TRIPP, 2005; TOLEDO e JACOBI, 2013), os alunos desenvolveram projetos diferentes, cada qual com o conceito resultante do processo criativo descrito.

O resultado do projeto foi a proposta dos produtos. Do conceito de tramas, nasceu uma série de referências e experimentações com tranças e amarrações para a elaboração de redes de tecidos. No conceito de encaixes, foram usados de palitos de 
picolé a pallets, para decidir que seria melhor trabalhar com compensado náutico cortado na fresadora do laboratório da universidade para a construção de bancos de madeira.

"- Que material? Quem compra? Como executamos?". Em cada um dos grupos havia responsabilidades compartilhadas como as de registro, compra de materiais, gestão dos gastos e montagem para a prototipagem, que aconteceu como um estudo de possibilidades na etapa de projeto.
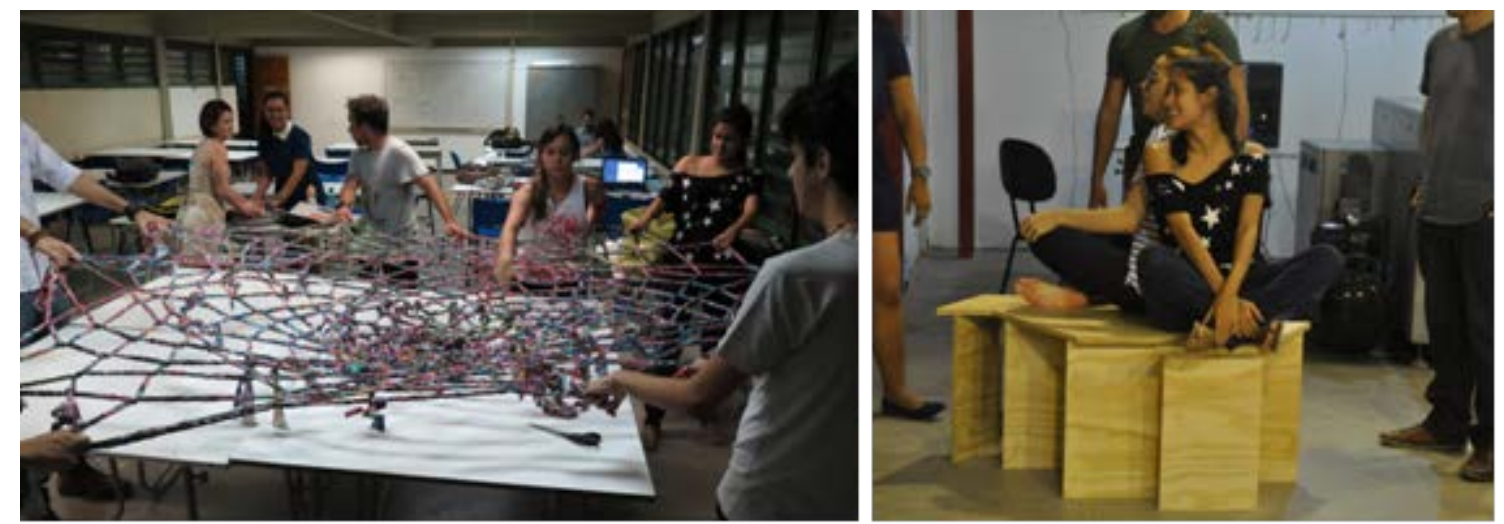

Imagens 6 e 7- Processos de prototipagem. Fonte: Rafael Moreira.

Durante os processos dos projetos - das idealizações iniciais, no papel, às experimentações dos objetos in loco, deu-se a captura das imagens de cada etapa por diferentes membros do grupo que, por se identificarem com o ofício, acabaram por priorizá-lo. As fotografias realizadas tiveram como objetivos principais o registro e a documentação de momentos que se mostraram relevantes para futuros entendimento e análise das experiências. Além das fotos, no final de cada aula algum aluno se responsabilizava por publicar na internet um resumo da aula e a decisão do encaminhamento para aula seguinte, para o registro e para quem faltou.

Em um projeto, todas as etapas pelas quais o designer passa se mostram de valiosa importância no seu resultado final. De acordo com Munari (2000), o processo de design é um conjunto de operações necessárias, dispostas em ordem lógica, que nos leva de forma segura e confiável à solução de um problema. Tendo isso em vista, a captura dos momentos que o concebem, por instrumentos que permitem a sua preservação, se mostra imprescindível no projeto por enfatizar cada etapa de modo singular e por colocá-las à luz de novas interpretações. As imagens possibilitam a investigação de espaços, técnicas e ferramentas, e proporciona o estudo detalhado do local abordado em questão e das pessoas que o frequentam.

Os registros se dispõem de forma a contar uma história, formando uma espécie de storyboard, sendo mais fácil, assim, visualizar erros e descobrir melhores soluções para problemas previamente encontrados. A visualização do processo de design abre novos caminhos para um segundo olhar sobre problemas que não foram completamente resolvidos ou que o foram de forma precária ou insuficiente. O relato do processo por imagens é fundamental para um segundo olhar àquilo que foi capturado, para a interpretação correta e compreensão satisfatória de momentos que passaram desapercebidos pelo olho desatento ou distraído dos autores do projeto. De acordo com Flusser (2002), o significado da imagem se encontra na superfície e pode ser traduzido com apenas um olhar. Porém, para maior aprofundamento do significado 
da fotografia, deve-se permitir o seu vagueamento, denominado pelo autor como scanning.

A fotografia foi utilizada de forma proveitosa, tanto durante quanto após o projeto, e ganhou destaque quando se mostrou vantajosa em vários aspectos, como a documentação do processo, o acompanhamento dos participantes dos outros grupos e para possíveis divulgações acadêmicas ou em outros meios, como o próprio blog. Em introdução à análise da imagem, Martine Joly (2007) discorre sobre como a contemplação de uma imagem pode ser benéfica para quem quer que a utilize: "Instrumento de comunicação, divindade, a imagem assemelha-se ou confunde-se com o que representa. Visualmente imitadora, pode enganar ou educar. Reflexo, pode levar ao conhecimento. (JOLY, 2007, p. 19)

\section{REALIZAÇÃO/IMPLEMENTAÇÃO/IMPLANTAÇÃO/INTERVENÇÃO/INTERAÇÃO}

“Este é outro saber indispensável à prática docente. O saber da impossibilidade de desunir o ensino dos conteúdos da formação ética dos educandos. De separar prática de teoria, autoridade de liberdade, ignorância de saber, respeito ao professor de respeito aos alunos, ensinar de aprender." (Freire, 2015, p. 93)

$\mathrm{Na}$ terceira linha de Didática, cada estudante deveria definir algo que gostariam que os outros, seus colegas cidadãos, aprendessem. Esse projeto de cidadania foi pensado originalmente de forma individual. Mas, para que fosse feito um exercício de cidadania dentro da própria sala de aula, foi pedido que os estudantes expusessem seus projetos individuais e chegassem a um acordo sobre um projeto coletivo que fosse planejado e realizado por todos junto à comunidade próxima (universidade e arredores).

Na disciplina de projeto, os alunos decidiram o local pela proximidade e a implantação dos dois protótipos foi realizada em uma praça a duas quadras da universidade, no horário da aula. Em pouco tempo pessoas que circulavam pelo espaço público interagiram com os objetos e com os alunos.
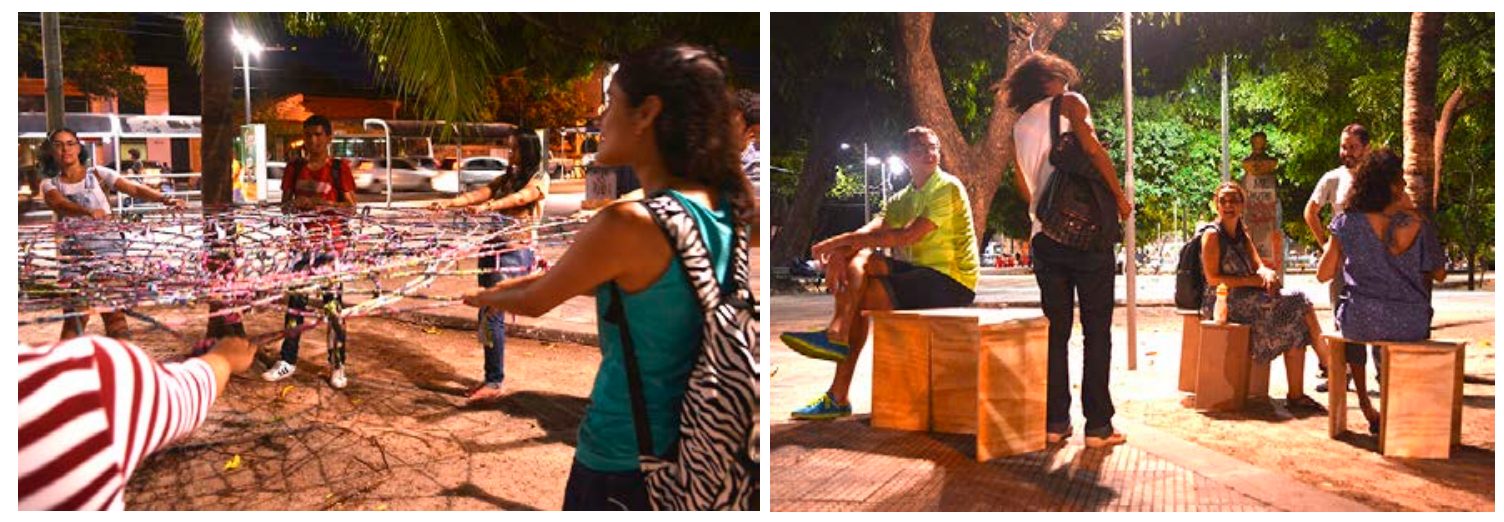

Imagens 8 e 9 - Instalação dos elementos na praça.

Fonte: co-autor, com base na pesquisa realizada.

Um primeiro momento foi de curiosidade, com a equipe montando a trama, mas os bancos foram logo utilizados. A Trama volta ao Laboratório, pois precisa de ajustes, sendo montada uma segunda vez, depois do recesso de final de ano. Sua segunda montagem, em outro contexto, se deu em meio a uma festa pré-carnavalesca 
com crianças brincando. Foi montada e lá esteve por duas semanas, sem intervenções de vandalismo, como corte ou mal tratos. Algumas pessoas questionaram, por sua forma e locação, se era um mobiliário, principalmente em termos de segurança. No entanto, ao se jogarem na Trama, surtiam expressões de surpresa ("- Pensei que não me aguentaria"), de conforto (“- Nossa, é confortável mesmo!"), e até mesmo de brincadeira "- Parece a rede do Homem-Aranha".

Levar para rua foi a etapa de projeto mais surpreendente entre os alunos. Definitivamente, os cercos da academia (projetos, pranchas e apresentações direcionadas a estudiosos) nem sempre são uma proposta enriquecedora. Design projetado para designers parece redutor. É valiosa a importância que devemos dar de trazer a sociedade, que mal compreende em si a própria terminologia Design, para opinar e discutir projetos dentro da universidade.

\section{REFLEXÕES, ARTIGO E PÔSTER}

"Saber que ensinar não é transferir conhecimento, mas criar as possibilidades para sua própria produção ou a sua construção." (Freire, 2015, p. 47)

Como trabalho integrado, conseguimos agregar os professores de Projeto Gráfico 4 na proposta colaborativa para o trabalho final, do último mês do semestre. Cada aluno elaborou um artigo e construiu um pôster, com o tema que escolheu. Houve trabalhos mais teóricos, outros analisaram a própria metodologia da disciplina ou os diferentes tipos de Design sistêmico implantados em situações colaborativas ou urbanas.

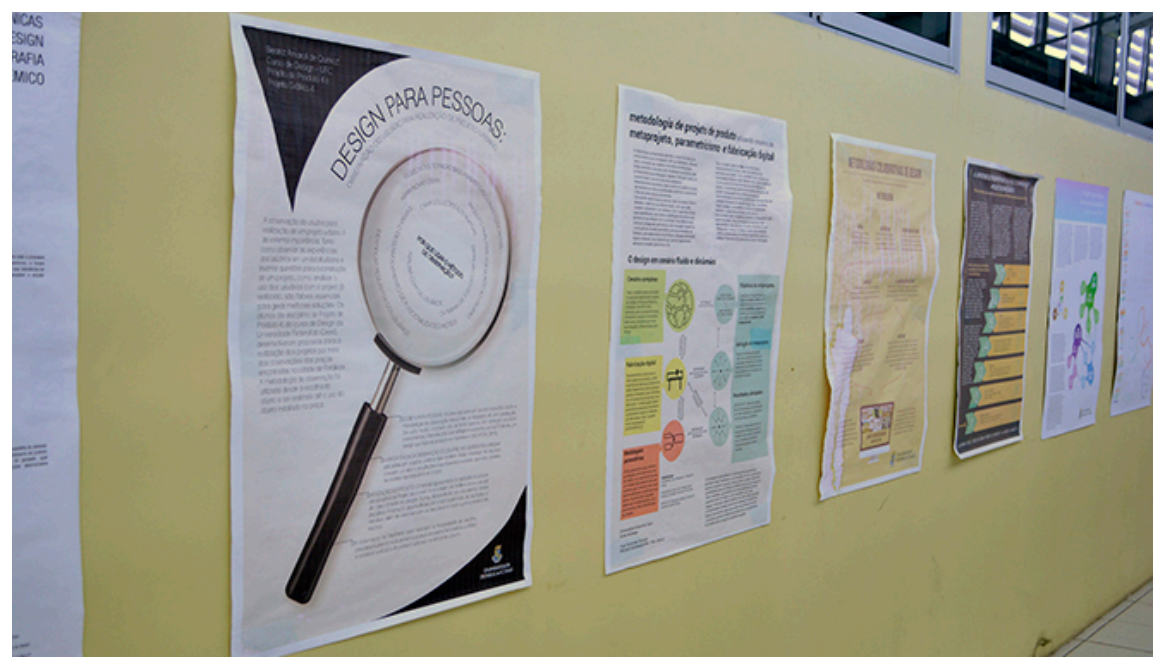

Imagem 10 - Exposição dos pôsteres dos alunos.

Fonte: co-autor, com base na pesquisa realizada.

Nesse procedimento final, houve uma reflexão sobre a validade e a importância de todo o processo, uma reflexão que teve uma abrangência de aprendizado didático, prático e pessoal. Os alunos sugeriram que esta experiência fosse aplicada nas disciplinas de projeto que antecedem PP4, com o reconhecimento da formação gradativa de autonomia e liberdade para a construção de seus próprios passos. 


\section{CONCLUSÃO}

"Ao investigar e agir, pesquisadores e atores sociais desenvolvem um processo de aprendizagem coletiva, já que os resultados encontrados no decorrer do processo oferecerão novos ensinamentos a todos." (TOLEDO, JACOBI, 2013, p. 161)

Todos aprenderam. Todos ensinaram. Na avaliação final, com os professores do projeto integrado, os alunos pediram que esse processo continue e, se possível, que seja aplicado nas outras disciplinas, antes da reta final do curso. A metodologia da disciplina de Didática ganha uma abrangência de necessidade no curso de Design. Precisamos ter voz para dar voz aos processos inclusivos, aos alunos que ensinam, aos professores aprendizes, alinhados pelo horizonte dos olhares, dos conhecimentos compartilhados e da troca de saberes.

\section{REFERÊNCIAS}

ALVES, Rubem. A alegria de ensinar. Campinas: Papirus, 2003. Disponível na internet em http: <http://www.virtual.ufc.br/cursouca/modulo_3/6994779-Rubem-Alves-AAlegria-de-Ensinar.pdf>. Acesso em: 15 abr. 2015.

BARBIÈR, Renè. A Pesquisa Ação. Tradução Lucie Didio. Brasília: Libel Livros, 2007. BONSIEPE, Gui. Design como prática de projeto. São Paulo: Blucher, 2012.

Design, Cultura e Sociedade. São Paulo: Blucher, 2011.

CAMPOS, F. et al. Cooperação e aprendizagem on-line. Rio de Janeiro: DP\&A, 2003.

CARDOSO, Rafael. Design para um mundo complexo. São Paulo: Cosac Naify, 2012.

FLUSSER, Vilém. Filosofia da caixa preta: ensaios para uma futura filosofia da fotografia. Rio de Janeiro: Relume Dumará, 2002.

FREIRE, Paulo. Pedagogia da autonomia: saberes necessários à prática educativa. Rio de Janeiro: Paz e Terra, 2015.

Educação como Prática da Liberdade. Rio de Janeiro: Paz e Terra, 1967.

JOHNSON, David W; JOHNSON, Roger T; SMITH, Karl A. A Aprendizagem Cooperativa Retorna às Faculdades: Qual é a Evidência de que Funciona? in Change, Jul/Aug98, Vol. 30, Issue 4.

JOLY, Martine. Introdução à Análise da Imagem, Lisboa, Ed. 70, 2007.

KRIPPENDORFF, Klaus. Design centrado no ser humano: uma necessidade cultural. Tradução Gabrielle Meireles. Estudos em Design, Rio de Janeiro: Associação de Ensino de Design do Brasil, v. 8, n. 3, p. 87-98, setembro de 2000.

LAWSON, Bryan. Como Arquitetos e Designers Pensam. Tradução Maria Beatriz Medina. São Paulo: Oficina de Textos, 2011.

LEFEBVRE, Henri. A Revolução Urbana. Tradução Sérgio Martins. Belo Horizonte: UFMG, 2008. 
LÖBACH, B. Design industrial: bases para a configuração dos produtos industriais. São Paulo: Edgar Blusher, 2001.

MORAES, Dijon. Metaprojeto: o design do design. São Paulo: Blucher, 2010.

MUNARI, Bruno. Das coisas nascem coisas. São Paulo: Martins Fontes, 1998.

NOJIMA, Vera; ALMEIDA JR, Licínio; RIBEIRO, Adriana B. Um plano metodológico para um projeto de pesquisa em design. Estudo e prática de metodologia em design nos cursos de pós-graduação. Rio de Janeiro: Novas Ideias, 2011.

NORMAN, Donald. Design do dia a dia. Rio de Janeiro: Rocco, 2006.

OVEJERO, B. A. Métodos de Aprendizagem Cooperativa. PPLL. Espanha: 1990.

Disponível em: http://www.teresianasstj.com/index.php/metodologias/aprendizagem/161metodos-de-aprendizagem-cooperativa. Consultado em 21 de abril de 2015.

POL, Enric. Cognición, representación y apropiación del espacio. Barcelona: Universidad de Barcelona, 1996.

RANCIÈRE, Jacques. O Espectador Emancipado. Tradução Daniele Ávila - Questão de Crítica, 2008. Disponível em: <http://www.questaodecritica.com.br/2008/05/oespectador-emancipado>. Acesso em: 29 abr. 2013.

SANTOS, Boaventura de Sousa. A universidade do século XXI: para uma reforma democrática e emancipatória da universidade. 3. ed. São Paulo: Cortez, 2010.

SANTOS, Milton. A Natureza do Espaço: técnica e tempo, razão e emoção. São Paulo: Hucitec, 1997.

SCHÖN, Donald. Educando o profissional reflexivo: um novo design para o ensino e a aprendizagem. São Paulo: Artmed, 2000.

TORRES, Patrícia Lupion. Laboratório on-line de aprendizagem: uma proposta crítica de aprendizagem colaborativa para a educação. Tubarão: Ed. Unisul, 2004.

TOLEDO, R. F.; JACOBI, P. R. Pesquisa-ação e educação: compartilhando princípios na construção de conhecimentos e no fortalecimento comunitário para o enfrentamento de problemas. Educação \& Sociedade, Revista de Ciência da Educação. CEDES, Campinas, v. 34, n. 122, p. 155-173, jan-mar. 2013.

TRIPP, David. Pesquisa Ação: uma Introdução Metodológica. Tradução Lélio Lourenço de Oliveira. Educação e Pesquisa, São Paulo, v. 31, n. 3, p. 443-466, set./dez. 2005.

VERMEREN, Patrice; CORNU, Laurence; BENVENUTO, Andrea. Atualidade de O Mestre Ignorante - entrevista com Jacques Rancière. Educação e Sociedade, v. 24, n. 82, p. 54- 61, 2003. Disponível na internet por http em: <http://www.scielo.br/pdf/es/v24n82/a09v24n82.pdf>. Acesso em: 20 maio 2015. 